\title{
Water-Soluble Poly(ethylenimine)-Based Nitric Oxide Donors: Preparation, Characterization and Potential Application in Hemodialysis
}

\author{
Zhengrong Zhou ${ }^{\mathrm{a}}$, Gail M. Annich ${ }^{\mathrm{b}}$, Yiduo Wu ${ }^{\mathrm{a}}$, and Mark E. Meyerhoff ${ }^{\mathrm{a}}{ }^{*}$ \\ a Department of Chemistry, The University of Michigan, Ann Arbor, Michigan 48109-1055 \\ b Pediatric Critical Care Medicine, The University of Michigan, Ann Arbor, Michigan 48109-2043
}

\begin{abstract}
A novel approach to potentially resolve serious thrombosis issues associated with kidney dialysis (hemodialysis) therapies is described. New water-soluble polymeric nitric oxide (NO) donors, based on the diazeniumdiolated branched poly(ethylenimine)s and their derivatives, are prepared and characterized. These macromolecular NO donors (with up to $4.15 \mu \mathrm{mol} / \mathrm{mg}$ of total NO release) are utilized as additives to the dialysate solution of model dialysis filters. The presence of these species can create a localized increase in NO levels at the high surface area dialysis fiber/blood interface within the hemodialyzers. Nitric oxide is a naturally occurring and potent anti-platelet agent, and is expected to greatly decrease the risk of thrombosis in the dialysis units.
\end{abstract}

\section{Introduction}

Healthy kidneys perform their life-sustaining job of removing toxic waste products and excess fluid from the body, maintaining a stable balance of body chemicals. When renal failure occurs in end-stage kidney disease patients, dialysis (i.e., hemodialysis) must be performed to sustain life. Generally, hollow dialysis fibers, the key component of hemodialyzers, use cellulose or polysulfone membranes in place of the phospholipid-bilayer membranes in real kidneys to separate the components of blood. Such semi-permeable membranes, with a given molecular weight cut-off (approx. 10-50 kDa), allow small waste molecules to pass through them into a flowing recipient solution (dialysate solution) and be removed from the blood. However, due to the highly porous surface structure of the dialysis fibers and their direct contact with blood, systemic or localized anticoagulation (e.g., with heparin) is usually required to reduce the risk of clot formation during such clinical procedures. ${ }^{1}$ The systemic administration of heparin can produce hemorrhagic complications in patients at high risk of bleeding, including intracranial hemorrhage. $^{2,3}$ To reduce these bleeding risks, alternative dialysis therapies have been developed without systemically heparinizing the patients. ${ }^{4}$ One of the most widely used clinical methods is to locally anticoagulate the blood within the dialysis system by lowering ionic calcium concentration via the continuous addition of citrate to the blood. ${ }^{5,6}$ Although this approach reduces the increased risk of bleeding, it requires continuous re-introduction of calcium into the blood stream prior to re-entry of the blood into the patient and hence frequent measurements of ionized calcium levels to ensure proper physiological levels.

To whom correspondence should be addressed at: 930 N. University Ave., The University of Michigan, Ann Arbor, MI 48109-1055. Email: mmeyerho@umich.edu. Tel: 734-763-5916. Fax: 734-647-4865. 
A potentially less risky but more convenient solution to the problem of thrombogenicity of the polymeric membranous fiber surface may now be realized via the addition of a water-soluble polymeric nitric oxide (NO) releasing additive to the dialysate solution, which is capable of spontaneously releasing a controlled level of NO through the porous membranous fibers at the polymer/blood interface. Due to the size of the molecule, ideally only NO would pass through the fibers, while the NO donor molecule would remain within the dialysate solution because of its high molecular weight/large hydrodynamic volume (see Figure 1). Indeed, NO is a naturally occurring, potent anti-platelet agent produced by endothelial cells that line the inner walls of all blood vessels, with a typical NO flux from the endothelial layer of $0.5-4 \times 10^{-10}$ $\mathrm{mol} \cdot \mathrm{cm}^{-2} \cdot \min ^{-1} \cdot{ }^{7-10}$ Polymeric coatings that release NO with similar fluxes have already been shown to greatly decrease the risk of thrombosis in various blood contacting medical devices. ${ }^{11-18}$ It is envisioned that, with this novel approach to improve the blood compatibility of dialysis filters, heparin- and citrate-free dialysis therapy may be performed without the concern of either clotting or excess bleeding. Moreover, the use of such an NO-release dialysis approach would be safe and convenient method to efficiently deliver NO to the point-of-care (compared to the use of a high-pressure NO gas cylinder), and only a small amount of such an additive would need to be stored/used for each dialysis treatment. Indeed, this scheme would not require major modification of the basic hemodialyzer design that is currently used in the clinical arena.

$\mathrm{N}$-Diazeniumdiolates are ideal NO donor candidates to realize the above concept. Their protonmediated NO release property ${ }^{19}$ has been widely utilized in developing localized NO delivery prodrugs for clinical applications (i.e., small molecule diazeniumdiolated proline as injectable ultrafast NO donor ${ }^{20}, 21$ ) as well as NO releasing hydrophobic polymer coatings $17,18,22-$ 27 and particles as filler materials $15,28,29$ (i.e., NO releasing crosslinked PEI microsphere - a water-insoluble particle for modifying vascular grafts ${ }^{29}$ ) for biomedical applications. However, no such NO donors have been reported to date that possess all the three unique characteristics necessary to carry out dialysis therapy without anticoagulation. These characteristics are: (1) polymer-based molecules that prevent leaching; (2) molecules which are highly water-soluble for convenient use; and (3) rapid NO release rates for high efficiency. To this end, we designed, synthesized and investigated three new types of branched poly (ethylenimine) (PEI)-based NO releasing agents (utilizing sodium-stabilized $\mathrm{N}$ diazeniumdiolates). Further, the first data from conceptual experiments related to artificial kidney dialysis (hemodialysis) therapies using such water-soluble polymer-based NO donors as dialysate additives are reported herein.

\section{Experimental Section}

\section{Materials}

Water-free low molecular weight branched PEI (LMwPEI, Mw=800, PDI=1.3, molar ratio of primary/secondary/tertiary amine=approx. 1/2/1) and high molecular weight branched PEI (HMwPEI, Mw=25,000, PDI=2.5, molar ratio of primary/secondary/tertiary amine=approx. 1/1.2/0.76) were purchased from Aldrich (Milwaukee, WI). HMwPEI was pre-treated via dialysis against DI water using Spectra/Pro 7 RC dialysis tubing (MWCO: $50 \mathrm{kDa}$, Spectrum Laboratories, Rancho Dominguez, CA) for ca. one week. The large molecular weight cut-off tubing was used to facilitate the dialysis process and the remaining high molecular weight fraction of the $\mathrm{HMwPEI}$ in the dialysis tubing was then lyophilized prior to further reactions. Methanol was dried over $4 \AA$ molecular sieves and tetrahydrofuran (THF) was distilled over sodium/benzophenone ketyl under nitrogen prior to use. Boc-L-proline hydroxysuccinimide ester and the sodium salt of poly(acrylic acid) (PAANa, $\mathrm{Mw}=5,100)$ were used as received from Fluka (Ronkonkoma, NY), and succinic anhydride, sulfanilamide and $N$-(naphthyl) ethylenediamine dihydrochloride were purchased from Aldrich. 3-(2-Furoyl)quinoline-2carboxaldehyde (FQCA) was obtained from Molecular Probes (Eugene, OR). Two types of 
hemodialyzers were used in the dialysis experiments: a Baxter ${ }^{\mathrm{TM}}$ Cellulose Triacetate Hollow Fiber Dialyzer-Model CT·110G (Baxter Healthcare Corporation, Deerfield, IL) and a Minifilter ${ }^{\mathrm{TM}}$ Plus Hemofilter (Minntech Corporation, Minneapolis, MN).

\section{Measurements}

${ }^{1} \mathrm{H}$ NMR spectra were obtained on a Varian $400 \mathrm{MHz}$ spectrometer (solvent= $\mathrm{D}_{2} \mathrm{O}$ ). FT-IR spectra were collected on a Perkin Elmer spectrum BX FT-IR system. UV absorbance spectra were recorded using a Perkin Elmer Lambda 35 spectrometer. Fluorescence measurements were conducted using a Shimadzu RF-1501 spectrofluorometer. All NO measurements were performed using a Sievers- $280^{\mathrm{TM}}$ chemiluminescence-based Nitric Oxide Analyzer (CL NOA, Boulder, $\mathrm{CO}$ ). The instrument was calibrated before each experiment using an internal twopoint calibration (zero gas and $45 \mathrm{ppm} \mathrm{NO}(\mathrm{g})$ ). The flow rate was set to $200 \mathrm{~mL} / \mathrm{min}$ with a cell pressure of 5.4 torr and an oxygen pressure of 6.0 psi. Nitric oxide released from all the diazeniumdiolated polymers was continuously swept from the headspace of the sample vessel, and purged from the test solution with a nitrogen sweep gas and bubbler into the CL NOA. To quantify the total amount of NO released, all the measurements were carried out for 2-3 d in $100 \mathrm{mM}$ phosphate buffer at $37^{\circ} \mathrm{C}$ with the addition of a diluted acid at the end of each experiment to completely decompose any residual intact $\mathrm{NO}$ donor within the polymer structure. Thermogravimetric analysis (TGA) was performed on a Perkin-Elmer TGA 7 under nitrogen. The TGAs were heated at a rate of $20^{\circ} \mathrm{C} / \mathrm{min}$, and decomposition temperatures were reported at a $10 \%$ weight loss.

\section{Synthesis of Diazeniumdiolated Branched PEls (3-6) (Scheme 1)}

Generally, a solution of $4 \mathrm{~g}$ of each PEI (low or high molecular weight, $\mathbf{1}$ or $\mathbf{2}$ ) in $20 \mathrm{~mL}$ of dry methanol and $60 \mathrm{~mL}$ of dry THF was prepared and placed in a high-pressure reactor (Parr bottle) with a stir bar. After flushing with argon for $10 \mathrm{~min}$, sodium methoxide ( 0.2 or 1 eq with respect to the total amine sites) in methanol was added and the reactor was then closed. The Parr bottle was purged with argon thoroughly to remove residual oxygen and subsequently charged with $\mathrm{NO}_{(\mathrm{g})}$ at 80 psi. The reaction mixture was stirred at room temperature for $72 \mathrm{~h}$ and then the NO was vented and the reactor was flushed with argon before each product was precipitated with dry THF/ether. The solvent was quickly removed by filtration, and the product was washed with dry ether and then vacuum dried to yield a light yellow powder (3-6) (Yield $=49.2-74.8 \%$ ). The diazeniumdiolated products were stored in sealed vials charged with argon in the freezer for long-term stability. TGA, $10 \%$ weight loss $\mathrm{T}_{(\mathbf{3})}=105^{\circ} \mathrm{C}, \mathrm{T}_{(\mathbf{5})}=108^{\circ} \mathrm{C}$.

\section{Synthesis of Carboxylated-PEI (7) and its NO Adduct (8) (Scheme 2)}

To a solution of $5 \mathrm{~g}$ of HMwPEI (2) in $100 \mathrm{~mL}$ of chloroform was added a solution of $1.16 \mathrm{~g}$ (11.6 mmol, $0.1 \mathrm{eq}$ ) of succinic anhydride in $50 \mathrm{~mL}$ of chloroform and $20 \mathrm{~mL}$ of THF. The reaction mixture was stirred at room temperature under argon for $6 \mathrm{~h}$ and then a white precipitate was collected by filtration, washed with acetone/ether, and then vacuum dried to provide $2.3 \mathrm{~g}\left(38.0 \%\right.$ ) of carboxylated-PEI (7). TGA, $10 \%$ weight loss $\mathrm{T}=200{ }^{\circ} \mathrm{C}$.

To a suspension of $1.1 \mathrm{~g}$ of (7) in $60 \mathrm{~mL}$ of dry methanol placed in a $\mathrm{NO}$ reactor under argon flow was added $4.7 \mathrm{~mL}$ of $\mathrm{NaOMe} / \mathrm{MeOH}$ solution $(4.37 \mathrm{M})$ followed by the addition of 30 $\mathrm{mL}$ of dry THF. After the general NO loading and workup procedures as described above for PEI/NOs, $1.56 \mathrm{~g}(69.7 \%)$ of white powder $(\mathbf{8})$ was obtained. The diazeniumdiolated product was stored in the freezer as described above. TGA, $10 \%$ weight loss $\mathrm{T}=178{ }^{\circ} \mathrm{C}$. 


\section{Synthesis of Boc-L-Proline-Incorporated PEI (9), and the Corresponding Deprotection (10) and NO Addition (11) Products (Scheme 3)}

Three $\mathrm{g}$ of HMwPEI (2) and $3 \mathrm{~g}$ of Boc-L-proline hydroxysuccinimide ester were dissolved in $200 \mathrm{~mL}$ of borate buffer ( $50 \mathrm{mM}, \mathrm{pH} 8.4$ ) to form a foggy solution. After stirring at room temperature for $1 \mathrm{~d}$, the resulting clear solution was dialyzed against DI water using dialysis tubing (MWCO: $50 \mathrm{kDa}$ ), and then lyophilized to provide $3.87 \mathrm{~g}(79.0 \%)$ of white powder (9). TGA, $10 \%$ weight loss $\mathrm{T}=233{ }^{\circ} \mathrm{C}$.

To deprotect (9), $20 \mathrm{~mL}$ of trifluroacetic acid (TFA) was added slowly to a solution of $2.47 \mathrm{~g}$ of (9) in $70 \mathrm{~mL}$ of chloroform. A sticky precipitate formed during the addition and the stirring was stopped. The reaction mixture was then sonicated for $2 \mathrm{~h}$ and stirring was resumed at room temperature for another $2 \mathrm{~h}$. After removal of solvent in vacuo, the residual was dissolved in $20 \mathrm{~mL}$ of water and neutralized with sodium bicarbonate solution. The resulting solution was dialyzed against DI water using dialysis tubing (MWCO: $50 \mathrm{kDa}$ ), and finally was lyophilized to quantitatively yield $2.09 \mathrm{~g}$ of off-white powder (10). TGA, $10 \%$ weight loss $\mathrm{T}=208{ }^{\circ} \mathrm{C}$.

To form the diazeniumdiolate of $(\mathbf{1 0})$, a solution of $1 \mathrm{~g}$ of $(\mathbf{1 0})$ in $40 \mathrm{~mL}$ of dry methanol and of $80 \mathrm{~mL}$ dry THF was first prepared, and $3 \mathrm{~mL}$ of $\mathrm{NaOMe} / \mathrm{MeOH}$ solution $(4.37 \mathrm{M})$ was then added under argon. The NO reactor was closed and followed by the general NO loading and workup procedures as described above to provide $1.3 \mathrm{~g}(61.2 \%)$ of light yellow powder (11). The diazeniumdiolated product was stored as described previously. TGA, $10 \%$ weight loss $\mathrm{T}=169^{\circ} \mathrm{C}$.

\section{Nitrite-Release Measurements via Griess Assay}

Twenty $\mathrm{mg}$ of each polymer $(\mathbf{5 , 8}$ or $\mathbf{1 1})$ was dissolved in $20 \mathrm{~mL}$ of $10 \mathrm{mM}$ deoxygenated $\mathrm{NaOH}$ solution ( $\mathrm{pH} 11.4)$ and placed in a dialysis tubing with a molecular weight cut-off of $15 \mathrm{kDa}$. The $\mathrm{NO}$ donor solution was dialyzed against $1 \mathrm{~L}$ of $10 \mathrm{mM} \mathrm{NaOH}$ with continuous stirring and nitrogen bubbling at room temperature. At selected time intervals (i.e., each hour for the first four hours and every day for three days), an aliquot of the $\mathrm{NaOH}$ dialysis solution was collected, neutralized, and the concentration of nitrite ion released from the polymer was measured via the Griess assay. ${ }^{30}$ Briefly, $100-\mu \mathrm{L}$ samples were pipetted into a 96 -well microtitier plate, neutralized with $0.5 \mathrm{M} \mathrm{HCl}$ and chilled to $4^{\circ} \mathrm{C}$. Then $40 \mu \mathrm{L}$ of a $1: 1$ mixture of $6 \mathrm{M} \mathrm{HCl}$ and $12.5 \mathrm{mM}$ sulfanilamide was added to each sample. After the samples were chilled for an additional $10 \mathrm{~min}$ at $4{ }^{\circ} \mathrm{C}, 20 \mu \mathrm{L}$ of $12.5 \mathrm{mM} N$-(naphthyl)ethylenediamine dihydrochloride (NEDA) was then added to form an azo compound whose concentration is directly proportional to the concentration of nitrite. After 15-min incubation at room temperature, the concentration of the azo compound can be determined by its maximum absorbance at $540 \mathrm{~nm}$ as measured via a Labsystems Multiskan RC 96-well microplate reader.

\section{Dialysis Experiments}

A Baxter ${ }^{\mathrm{TM}}$ dialyzer (for adults, surface area $=1.1 \mathrm{~m}^{2}$ ) and a Minifilter ${ }^{\mathrm{TM}}$ (for infants, surface area $=0.08 \mathrm{~m}^{2}$ ) were employed in the model dialysis system as shown in Figure 2. The porous membranous fibers (blood pathway) within the dialyzer were in contact with a large volume of dialysate solution flowing continuously in the dialysate pathway. A stream of basic (high $\mathrm{pH})$ water-soluble polymeric $\mathrm{NO}$ donor stock solution $(1 \mathrm{mg} / \mathrm{mL}$, prepared in $\mathrm{pH}>8$ buffer $)$ was infused into a stream of deoxygenated phosphate-buffered saline (PBS, a dialysate substitute containing $138 \mathrm{mM} \mathrm{NaCl}$ and $2.7 \mathrm{mM} \mathrm{KCl}, \mathrm{pH}$ 7.4) and completely mixed in a 3.6 $\mathrm{m}$ mixing loop prior to entering the dialyzer. The flow of PBS buffer was controlled at the rate of 15 or $33 \mathrm{~mL} / \mathrm{min}$, mimicking the rate of the dialysate solution used with the Baxter ${ }^{\mathrm{TM}}$ dialyzer or Minifilter ${ }^{\mathrm{TM}}$ in clinical treatments. The water-soluble polymeric NO donor solution was infused at a varying rate in the range of $0.5-4 \mathrm{~mL} / \mathrm{min}$. The $\mathrm{NO}$ gas that is generated in the dialysate solution, which diffuses through the dialysis fiber walls to the blood pathway, was 
flushed with a nitrogen flow to a chemiluminescence-based $\mathrm{NO}$ analyzer. After the experiments, the NO levels were plotted vs. time with Excel.

\section{Leaching Experiments}

Nitric oxide adduct $(\mathrm{HMwPEI} / \mathrm{NO}, \mathbf{5})$ was chosen as a representative polymer for leaching studies using a hemodialyzer. The degree of leaching of any nitrite side-products and the polyamine decomposition products through the membranous fiber to the blood pathway was evaluated via a similar set-up as shown in Figure 2. Instead of using a nitrogen flow, a deoxygenated PBS buffer solution ( $10 \mathrm{mM}, \mathrm{pH} 7.4)$, maintained at $37^{\circ} \mathrm{C}$ and a fixed volume of $150 \mathrm{~mL}$, was continuously circulated through the blood pathway at a rate of $12 \mathrm{~mL} / \mathrm{min}$, equilibrating with a countercurrent flow of dialysate solution (rate $=5.5 \mathrm{~mL} / \mathrm{min}$ ) containing $\mathrm{HMwPEI} / \mathrm{NO}(0.1 \mathrm{mg} / \mathrm{mL})$. An aliquot of the circulated solution from the blood pathway was collected every hour for four hours, bubbled with nitrogen for $30 \mathrm{~min}$ and then stored at $4{ }^{\circ} \mathrm{C}$ for further testing. The concentration of the nitrite in these solutions was determined by the Griess assay as described above. The degree of the polyamine leachables were evaluated with a fluorescence-based method for primary amine detection. ${ }^{28}$ Briefly, an aliquot of the sample solution was incubated in darkness at room temperature with a fluorescent precursor (FQCA) in the presence of $\mathrm{KCN}$ for $1 \mathrm{~h}$. The resulting products are fluorescent FQ-polyamines. Fluorescence measurements were made with an excitation wavelength of $494 \mathrm{~nm}$ and emission spectra were recorded from 500 to $600 \mathrm{~nm}$ using a spectrofluorometer equipped with a 500 nm-yellow filter.

\section{Results and Discussion}

\section{Synthesis and Characterization of NO Releasing Polymers}

Three different types of water-soluble polymeric NO donors, based on diazeniumdiolated branched PEIs and their derivatives, were synthesized and characterized (see Schemes 1-3 and Table 1).

Diazeniumdiolation reactions were first directly carried out on two branched PEI starting materials in the presence of varying amounts of sodium methoxide. LMwPEI (1) was used only for studying the basic NO loading/releasing chemistry of its NO adducts, not for dialysis purposes. HMwPEI (2) was pre-dialyzed with a molecular weight cut-off of $50 \mathrm{kDa}$ dialysis tubing in order to remove any low molecular weight fractions of the PEI, and therefore to potentially prevent leaching problems in the future dialysis experiments. All the resulting NO adducts (3-6), bearing ionic sodium-stabilized diazeniumdiolate functional groups, maintained their high water-solubility after NO addition. As shown in Table 1, the direct NO addition reactions afforded $49-75 \%$ yields for the final products, with a notably increased yield (see the third column of the table) when higher amounts of sodium methoxide was used. The increased amount of base did not result in significant increases in the percentage of diazeniumdiolation (see the last column in Table 1) for both LMwPEI and HMwPEI. It is likely that with the increased amount of base, most primary amine sites will not be able to form stable diazeniumdiolates ${ }^{31}$ while the available number of secondary amine sites in each structure that can form stable diazeniumdiolates may be limited by steric effects.

The UV-vis absorption spectra of all the diazeniumdiolated PEIs (3-6) show the characteristic absorption band for diazeniumdiolates at ca. $250 \mathrm{~nm}$ as measured in $10 \mathrm{mM}$ deoxygenated PBS buffer at $26{ }^{\circ} \mathrm{C} .{ }^{32}$ Using reaction conditions described in the experimental section, no detectable $N$-nitrosamine species (with UV absorbance bands in the range of 330-360 nm ${ }^{33}$ ) were found to form within the final polymers. The structural characterization of the representative product (5) using ${ }^{1} \mathrm{H}$ NMR and IR is shown in Figure 3. Upon diazeniumdiolation, a portion of the proton signals $(\boldsymbol{a})$ at $2.4 \mathrm{ppm}$ (methylene groups adjacent 
to amine site in HMwPEI) are downfield shifted to $(\boldsymbol{b})$ at approx. $2.8 \mathrm{ppm}$, due to the electron withdrawing effect of the diazeniumdiolate group. The integration of the shifted proton signals compared to the total proton integration of the compound (5) suggests $27 \%$ of the theoretical diazeniumdiolation (not considering other side reactions). This agrees well with the $24.9 \%$ diazeniumdiolation achieved for the same polymer as determined via the CL NOA measurements. The formation of the diazeniumdiolate group was also confirmed by the appearance of two distinct IR bands at 1363 and $945 \mathrm{~cm}^{-1}$ that were reported to be characteristic for the O-N-N-O asymmetric stretch and in-plane $\mathrm{N}_{2}$ symmetric stretch of the $\mathrm{N}_{2} \mathrm{O}_{2}{ }^{-}$group, respectively,, 34 as well as by the appearance of a large $\mathrm{OH}$ band around $3600 \mathrm{~cm}^{-1}$ that was from the absorbed moisture due to the hydroscopic nature of the diazeniumdiolated polymer. The former two bands decreased with time as the IR sample of polymer (5) was kept in an oven at $150{ }^{\circ} \mathrm{C}$ (nearly moisture-free condition) until they totally disappeared after two days, indicating the complete loss of all the diazeniumdiolate groups via thermal dissociation (spectra not shown here). However, such compounds are reasonably stable at room temperature (i.e., with approx. 8\% of total NO loss after 5-day storage under ambient conditions for polymer (5)) and their thermal dissociation can be eliminated completely by storage of diazeniumdiolated polymers in argon or nitrogen under $-20{ }^{\circ} \mathrm{C}$ for extended periods of time. This was proven by a long-term stability test of the NO donors after a 6-month storage under the above conditions (approx. $3 \%$ loss of NO over 6 months at $-20^{\circ} \mathrm{C}$ ). After this period, the total NO release from the representative compound (5) was found to be $3.62 \pm 0.35 \mu \mathrm{mol} / \mathrm{mg}$, not statistically different from that measured with the fresh samples $(3.74 \pm 0.41 \mu \mathrm{mol} / \mathrm{mg})$.

To obtain a PEI-based NO donor with a relatively fast NO release rate (discussed below), carboxylate sites (as inherent additive sites) were introduced to the polyamine substrate via the amidation reaction of HMwPEI (2) with succinic anhydride (0.1 eq in respect with the total amine sites). The appearance of two new IR bands at 1653 and $1405 \mathrm{~cm}^{-1}$ in the resulting product (7) confirms the $\mathrm{C}=\mathrm{O}$ and $\mathrm{C}-\mathrm{N}$ stretches of the incorporated $\mathrm{NC}(\mathrm{O}) \mathrm{CH}_{2} \mathrm{CH}_{2} \mathrm{COO}^{-}$ moieties (see Figure $2 \mathrm{~s}$ in the Supporting Information). Surprisingly, this compound was not soluble in water nor was it soluble in most organic solvents tested, making the selection of NO addition solvents difficult; however, upon addition of sodium methoxide prior to NO loading in $\mathrm{THF} / \mathrm{CH}_{3} \mathrm{OH}$, a clear solution was obtained. It is likely that sodium methoxide breaks the $\mathrm{COO}^{-} / \mathrm{NH}^{+} \mathrm{R}_{2}$ ion-pairs that may crosslink the polymer chains and decrease solubility. Final NO addition to (7) afforded nearly $70 \%$ of a highly water-soluble product $(\mathbf{8})$ with both characteristic UV absorption band and IR bands of the $\mathrm{N}_{2} \mathrm{O}_{2}{ }^{-}$group (see Figure $2 \mathrm{~s}$ in the Supporting Information). Although the introduction of carboxylate sites caused a decrease in the total NO loading of the final polymer (8) compared to the direct NO addition product (6) (2.92 vs. $3.84 \mu \mathrm{mol} / \mathrm{mg}$ ), the resulting NO release rate of PEI-COONa/NO was quite different than that of diazeniumdiolated PEIs without the appended carboxylate groups (see below).

The naturally occurring amino acid (L-proline) was previously reported to form ultrafast NO releasing species (PROLI/NO) after the diazeniumdiolation reaction. PROLI/NO has a halflife of less than $2 \mathrm{~s}$ as measured under physiological conditions. ${ }^{20,21}$ Tethering PROLI/NO onto polymer backbones would potentially result in a new type of polymeric NO donors with rapid NO release rates. To achieve this goal, PROLI/NO-incorporated PEI (11) was prepared by first anchoring Boc-protected L-proline onto the HMwPEI (2) structure, followed by Bocdeprotection to release free proline secondary amine sites for subsequent $\mathrm{NO}$ addition. This reaction was carried out in a borate buffer, $\mathrm{pH}$ 8.4, where Boc-L-proline hydroxysuccinimide ester has its optimal reactivity with PEI amine sites. Subsequently, the resulting small molecule $\mathrm{N}$-hydroxysuccinimide product and the remaining buffer salts, as well as possible hydrolytic products of Boc-L-proline hydroxysuccinimide ester, were completely removed via extensive dialysis, yielding $79 \%$ of Boc-L-proline-incorporated PEI (9). The typical proton NMR signals of the Boc-group at 1.2-1.3 ppm were used as a probe to quantify the degree of the Bocprotected L-proline incorporated within (9). It was found that $11.5 \%$ (theoretically $13.6 \%$, 
based on the initial feed ratio) of the total amine sites reacted with Boc-L-proline hydroxysuccinimide ester forming stable amide bonds (see Figure $3 \mathrm{~s}$ in the Supporting Information). The appearance of two overlapped $\mathrm{C}=\mathrm{O}$ bands (amide $=1696 \mathrm{~cm}^{-1}, \mathrm{Boc}=1667$ $\mathrm{cm}^{-1}$ ) in the IR spectrum confirms the formation of the desired structure (see Figure $4 \mathrm{~s}$ in the Supporting Information). The band at $1667 \mathrm{~cm}^{-1}$ disappeared after the deprotection reaction using TFA. This observation, in combination with the disappearance of the Boc signal in the NMR spectrum of (11), indicates complete Boc-deprotection. Diazeniumdiolation of this polymer (yield $=61.2 \%$ ) was successful, with stable diazeniumdiolates formed on the free secondary amine sites in the proline ring structure as well as on the free PEI secondary amine sites. Again, the final polymer (11) also shows both characteristic UV absorbance and IR bands of the $\mathrm{N}_{2} \mathrm{O}_{2}{ }^{-}$group (see Figure $4 \mathrm{~s}$ in the Supporting Information). It should be noted that this polymer provides the highest NO release $(4.15 \mu \mathrm{mol} / \mathrm{mg})$ among all the polymeric NO donors prepared in this study. It is very likely that the incorporation of the proline units converts a number of PEI primary amines, which do not readily form stable diazeniumdiolates, into an equivalent amount of secondary amine sites, thereby increasing the number of potential diazeniumdiolation sites.

\section{Decomposition and NO Release of Diazeniumdiolated Polymers}

$\mathrm{N}$-Diazeniumdiolates have been shown to decompose and release NO by two mechanisms, proton-driven ${ }^{19}$ and thermal ${ }^{14}$ dissociation. In the IR study discussed above, it was demonstrated that when the diazeniumdiolated polymer (HMwPEI/NO) was heated to $150{ }^{\circ} \mathrm{C}$ under the moisture-free conditions, only thermal dissociation occurred. When exposed to proton sources (i.e., PBS buffer) at $37^{\circ} \mathrm{C}$, both thermal and proton-drive dissociations can occur. However, given the fact (data not shown here) that the NO donors studied herein undergo very insignificant decomposition in dry $\mathrm{N}_{2}$ at physiological temperature (only thermal dissociation), it is assumed that their dissociation in deoxygenated buffer solution to release NO is primarily proton-mediated. Thus, the decomposition of water-soluble polymeric NO donors to release $\mathrm{NO}$ in aqueous solution was carefully investigated in this work under various conditions ( $\mathrm{pH}$, additive, temperature, etc.) using UV and chemiluminescence-based $\mathrm{NO}$ analyzer (NOA). Such studies revealed the basic properties of the different donors and provided important information for the formulation of such dialysate additives as well as for the design and optimization of the dialysis system using the proposed NO-release strategy.

It was found that HMwPEI/NO (5) exhibited substantially different NO release patterns in phosphate buffer at different concentrations, as shown in Figure 4. A low and sustained level of NO release was observed from (5) when measured in $10 \mathrm{mM}$ PBS buffer while dramatically faster NO release was found when measured in a $100 \mathrm{mM}$ phosphate buffer. This effect is not due to a difference in the ionic strength of the two buffers, since adding additional $\mathrm{NaCl}$ up to $198 \mathrm{mM}$ to the $10 \mathrm{mM}$ PBS did not change the rate of NO release observed with this buffer system. However, upon addition of an acid, the retained NO was spontaneously and completely released from (5) in $10 \mathrm{mM}$ PBS buffer. The $\mathrm{pHs}$ of the HMwPEI/NO test solutions made with $10 \mathrm{mM}$ PBS and $100 \mathrm{mM}$ phosphate buffer $(1 \mathrm{mg} / \mathrm{mL}$, originally $\mathrm{pH} 7.4)$ were found to be 9.2 and 7.5, respectively. This suggests that the basic polyamine structure within the PEI and any residual sodium methoxide can greatly affect the $\mathrm{pH}$ of a buffer solution with a relatively weak buffer capacity; therefore, this affects the NO release rate from the diazeniumdiolates within such a buffer, which is a highly $\mathrm{pH}$-dependent process. ${ }^{19}$ Indeed, this $\mathrm{pH}$ effect can be applied as the principle of NO release at the site of application (dialysis fibers) for the new NO-release dialysis system. The water-soluble polymeric NO donor is initially dissolved in a high $\mathrm{pH}$ buffer where its NO release should be greatly inhibited; however, dramatic NO release is stimulated spontaneously once this donor solution merges with a large amount of lower $\mathrm{pH}$ dialysis fluid in the mixing loop/dialyzer, creating a localized increase in NO level at the high surface area dialysis fiber/blood interface within the dialysis filters. 
The decomposition kinetics of (5) was studied using UV spectroscopy by monitoring the decrease of absorbance at $250 \mathrm{~nm}$ with time (see Figure 5). It was found that the decomposition of (5) in the physiological pH (7.4) at room temperature exhibits near-first-order behavior (plot of $\log$ [diazeniumdiolate concentration] vs. time yielded a straight line) with a rate constant of $3.9 \times 10^{-5} \mathrm{~s}^{-1}$ and a half-life of $5.0 \mathrm{~h}$ (300 min, see Figure 5, inset). This $t_{1 / 2}$ value indicates that $\mathrm{HMwPEI} / \mathrm{NO}(\mathbf{5})$ has a dramatically faster NO release rate than the previously reported NO releasing crosslinked PEI microsphere (PEIX/NO) with a calculated half-life of $66.2 \mathrm{~h}$ under the same conditions. ${ }^{29}$ The previous water-insoluble PEIX/NO was actually developed as a filler material for vascular grafts, which requires minimal leaching (maximal waterinsolubility) and slow NO release rate for long-term applications.

Chemiluminescence-based NOA was also employed to study the dissociation kinetics of the representative water-soluble diazeniumdiolated polymers-HMwPEI/NO (5), PEI-COONa/ $\mathrm{NO}(\mathbf{8})$ and PEI-PRO/NO (11) — but at physiological temperature $\left(37^{\circ} \mathrm{C}\right)$. The resulting kinetic data and NO release profiles of the polymers are compared in Table 2 and shown in Figure 6.

The decomposition of the polymeric NO donors was found to be temperature dependent; for example, compound (5) was observed to have a much faster $\mathrm{NO}$ release rate at $37{ }^{\circ} \mathrm{C}$ than at $26^{\circ} \mathrm{C}$, with a rate constant determined to be $6.0 \times 10^{-5} \mathrm{~s}^{-1}$ and a $t_{1 / 2}$ value of $192 \mathrm{~min}$. Interestingly, it was also found that the dissociation of (5) was greatly accelerated in the presence of the sodium salt of poly (acrylic acid) (PAANa, $1 \mathrm{mg} / \mathrm{mL}$ ), a heparin mimic with antithrombin-activating properties; 35,36 the resulting decomposition reaction also follows near-first-order kinetics, but has an even greater rate constant and a much shorter half-life $\left(k=1.6 \times 10^{-4} \mathrm{~s}^{-1}, t_{1 / 2}=72 \mathrm{~min}\right)$ in the presence of PAANa. Notably, the addition of a low concentration of PAANa did not affect the $\mathrm{pH}$ of the buffer at all, indicating that this was not a solution $\mathrm{pH}$ effect similar to that described above.

This finding inspired the design and synthesis of a faster NO release version of the original PEI material, PEI-COONa/NO (8), that contains pendant carboxylate sites within the same polymeric structure to speed $\mathrm{NO}$ release from the polymer. Indeed, $\mathrm{PEI}-\mathrm{COONa} / \mathrm{NO}$ was found to exhibit much faster NO release kinetics $\left(t_{1 / 2}=59.4 \mathrm{~min}\right)$ than $\mathrm{HMwPEI} / \mathrm{NO}(\mathbf{5})$. This rate is similar to the NO release of HMwPEI/NO in the presence of the PAANa additive. It is speculated that the carboxylate sites within $\mathrm{PEI}-\mathrm{COONa} / \mathrm{NO}$ serve to promote the decomposition speed of the surrounding diazeniumdiolate groups to release NO, similar to the function of the exogenous PAANa additive. As suggested in Scheme 4, it is likely that in the aqueous media, the carboxylate groups can form more stable acid-base ion-pairs with the neighboring amine sites that are created after the NO release reaction, thereby forcing the equilibrium toward the decomposition of the inter/intramolecular diazeniumdiolate groups and speeding NO release. It is also possible that substitution of carboxyl sites for amines on the polymer could decrease any stabilizing interaction between the pendant diazeniumdiolates and adjacent amines and/or the presence of the adjacent amines could contribute to stabilization by increasing the local $\mathrm{pH}$ near the diazeniumdiolate species. The latter is a more likely alternate to the mechanism suggested in Scheme 4; however, even the carboxylated PEI$\mathrm{COONa} / \mathrm{NO}$ donors have considerable amount of unmodified tertiary amine sites in the vicinity of the diazeniumdiolate groups, and hence one would think that these stronger base sites would likely control any microenvironmental $\mathrm{pH}$ effects that would control NO release rates. In the case of increased rates of NO release when PAANa is added separately to the test solution containing the PEI/NO species, it is possible that the PAANa complexes with the positively charged PEI/NO (owing the excess primary and tertiary amine sites still present on such polymers), and this interaction provides a local $\mathrm{pH}$ microenvironment from residual protons on the PAANa structure that increase the rate of reaction. Sorting these various possibilities out will require further studies. 
Among the three water-soluble PEI-based NO releasing materials, diazeniumdiolated Lproline-incorporated PEI (11) was found to be the most efficient NO donor (fastest and largest amount of total NO release, as shown in Figure 6) with a half-life of only $48 \min \left(37^{\circ} \mathrm{C}, \mathrm{pH}\right.$ 7.4). The decomposition of this candidate polymer was extensively studied at two other temperatures $\left(26\right.$ and $45^{\circ} \mathrm{C}$ ) and the half-lives were found to be 151.8 and $24.2 \mathrm{~min}$, respectively, showing the expected strong temperature-dependent NO release kinetics. This information is helpful for the future design of the NO-release dialysis system. The efficient NO release feature of (11) is mostly attributed to the covalently linked proline units within the PEI structure, which are loaded with NO. The diazeniumdiolated free proline (PROLI/NO) is the fastest NO donor reported to date. ${ }^{20}$ It should be noted that two types of diazeniumdiolate groups may exist within polymer (11): one on the proline amine sites (faster NO release) and the other on the PEI amine sites (slower NO release). Both ultimately contribute to the overall NO release speed of the compound. However, the NO release rate of PEI-PRO/NO (11) is substantially slower than that of its corresponding small molecule NO adduct PROLI/NO $\left(t_{1 / 2}: 48 \mathrm{~min}\right.$ vs. $2 \mathrm{~s}$, at $37^{\circ} \mathrm{C}$ ). It is likely that these significantly different half-lives can be attributed to the structural difference between the two species. Indeed, the PEI-based watersoluble polymeric NO donors contain a considerable amount of tertiary amines within the polymer structures, which cannot form diazeniumdiolates but may increase the microenvironment basicity, thereby enhancing the stability of the adjacent diazeniumdiolate groups.

The development of new NO donors based on polymer structures lacking tertiary amines is one possible approach to obtain faster versions of water-soluble polymeric NO donors for wider applications. Efforts to prepare such water-soluble NO donors by incorporating PROLI/NO onto high molecular weight poly(allylamine) backbone or linking mono-diazeniumdiolated piperazine onto carboxylmethyl cellulose structure are currently in progress in this laboratory.

It should be noted that the PEI materials used to create some of the water-soluble polymeric NO donors contain considerable levels of primary amines. Although diazeniumdiolates of primary amine groups are much less stable with respect to yielding NO release moieties, ${ }^{31}$ Keefer et al. reported that diazeniumdiolation of primary amines can, in some instances, produce adducts that release nitroxyl (HNO). ${ }^{37}$ To test whether polymer (5) produced any measurable levels of $\mathrm{HNO}$, along with $\mathrm{NO}$, a fluorescence assay of total NO/HNO was employed 38,39 and results were compared to total NO only release, as measured by chemiluminescence. A pH 6.4 phosphate buffer was used for these measurements, to speed the $\mathrm{NO} / \mathrm{HNO}$ release reactions. After $4 \mathrm{~h}$ of reaction at $37^{\circ} \mathrm{C}$, the total $\mathrm{NO} / \mathrm{HNO}$ measured by fluorescence was $6.5 \%$ greater than the moles of NO detected by chemiluminescence. This suggests that some small amount of HNO may, in fact, be released from polymer (5), but the level is much less than the total NO species that is produced by this new water-soluble polymeric NO donor agent.

\section{NO Release Studies for Potential Hemodialysis in a Static Setting}

To demonstrate that dramatically increased NO release can be created spontaneously upon mixing of a basic water-soluble polymeric NO donor stock solution and a dialysate fluid $(\mathrm{pH}$ 7.4) at a given volume ratio, static mixing experiments were designed and conducted. Different factors that could influence the amount of NO release were also investigated. As expected, NO release was inhibited as each NO donor was kept in a high $\mathrm{pH}$ buffer solution (Figure 7, IIII). The initial levels of NO detected from $100 \mu \mathrm{L}$ of the NO donor stock solutions were highly dependent on the stability (half-life) of the water-soluble polymeric NO donors; for example, $18 \mathrm{ppb}$ for HMwPEI/NO but $72 \mathrm{ppb}$ for PEIPRO/NO. Upon addition of $3300 \mu \mathrm{L}$ of buffer (10 $\mathrm{mM}$ PBS or $100 \mathrm{mM}$ phosphate buffer, $\mathrm{pH}$ 7.4), a significantly increased level of $\mathrm{NO}$ (up to $2800 \mathrm{ppb}$, at $37^{\circ} \mathrm{C}$ ) was observed. This experiment proves that the potent $\mathrm{NO}$ release potential 
of all the polymeric donors can be retained until they are merged with a stream of lower $\mathrm{pH}$ dialysate solution immediately prior to entering the hemodialysis filter.

The addition of a low dose of PAANa to the solution phase $(30 \mu \mathrm{g} / \mathrm{mL}, 5,100 \mathrm{Da}$ PAANa used herein only to demonstrate the effect but not for dialysis purposes) was found to effectively enhance the NO release level for all the polymeric donors (see Figure 7). The effect was most significant in the case of HMwPEI/NO where addition of PAANa enhanced NO release by a factor of 2.5-fold for both buffers tested. Such additive effect was also observed for PEI$\mathrm{COONa} / \mathrm{NO}$ and PEI-PRO/NO (up to 20 and $40 \%$ increase in NO level, respectively) though not as significant as for HMwPEI/NO. Furthermore, as shown in Figure 7, increasing the temperature plays an important role in generating higher levels of NO.

\section{NO Release Studies using Hemodialysis Filters in a Flowing System}

Finally, a commercial Baxter ${ }^{\mathrm{TM}}$ hemodialysis dialyzer (for adults, surface area $=1.1 \mathrm{~m}^{2}$ ) and a Minntech ${ }^{\mathrm{TM}}$ mini-filter (for infants, surface area $=0.08 \mathrm{~m}^{2}$ ) were employed in a flowing system, as shown in Figure 2, to demonstrate the concept of NO release for hemodialysis. Porous membranous fibers housed within the dialysis filters were continuously perfused with a large volume of flowing dialysate solution at a rate of $33 \mathrm{~mL} / \mathrm{min}$ (for Baxter ${ }^{\mathrm{TM}}$ dialyzer) or $15 \mathrm{~mL}$ / $\min$ (for Minntech ${ }^{\mathrm{TM}}$ mini-filter). In real clinical treatments, the blood that is removed from the patient's vein is pumped through these fibers in a countercurrent flow against the dialysate solution. The non-circulating dialysate solution is always removed as waste. The semipermeable membranous fibers, which are typically 10-20 $\mu \mathrm{m}$ thick, have a large surface area, with pores that have desired molecular weight cut-offs. Generally, molecules with a molecular weight less than 5,000 pass through the membranous fibers fairly easily. In this manner, toxic small molecule wastes, such as urea, can be removed from the body via the two-phase dynamic equilibrium. In these preliminary experiments, a stream of basic water-soluble polymeric NO donor solution $(1 \mathrm{mg} / \mathrm{mL}$ ) was merged with a stream of PBS buffer (a dialysate substitute, $\mathrm{pH}$ 7.4) within a mixing loop prior to entering the dialyzer. The length and pre-heating temperature of the mixing loop can be adjusted to achieve maximal/optimal NO fluxes at the membranous fiber/blood interface within the dialysis filters.

Figure 8 demonstrates that steady interfacial NO fluxes (up to $0.03 \times 10^{-10} \mathrm{~mol} \cdot \mathrm{cm}^{-2}$. $\mathrm{min}^{-1}$ ) can be generated and diffuse through the fiber walls of the Baxter ${ }^{\mathrm{TM}}$ dialyzer when using $\mathrm{HMwPEI} / \mathrm{NO}$ as the dialysate additive. Such NO levels can be controlled by simply varying the experimental conditions, such as mixing rate of the NO donor stock solution and pre-heating temperature. It should be noted that during the dialysis experiments, some water/buffer droplets were observed to diffuse through the dialysis fiber walls to the "blood-side" (gas phase) due to permeation equilibria between two phases. Such discontinuous droplets containing dissolved NO gas can cause spikes that are superimposed onto the stable NO fluxes generated by gas diffusion only (shown in both Baxter ${ }^{\mathrm{TM}}$ dialyzer and Minntech ${ }^{\mathrm{TM}}$ mini-filter cases). These spikes varied in the different experimental conditions as well as when dialysis filters made of different fibers were used.

The NO fluxes through the walls of the dialysis fibers can be greatly enhanced (by up to 2.5fold) via the addition of PAANa to the dialysate solution at a low dose of $30 \mathrm{mg} / \mathrm{L}$ (data not shown here). Although for safety considerations, high molecular weight PAANa can be used to prevent possible leaching into the blood side, it is noteworthy that PAANa has been reported to possess equivalent/near equivalent anticoagulation activity as low-affinity-heparin and other polysaccharide species. 35,36

In a second experimental set-up using the Minntech ${ }^{\mathrm{TM}}$ mini-filter (with $7 \%$ fiber surface area of the Baxter ${ }^{\mathrm{TM}}$ filter), steady-state NO interface fluxes (see Figure 9) were greatly increased by approx. 20 -fold when $\mathrm{HMwPEI} / \mathrm{NO}$ solution was mixed at a rate of $1 \mathrm{~mL} / \mathrm{min}$ at $26^{\circ} \mathrm{C}$, 
compared to the same infusion conditions with Baxter ${ }^{\mathrm{TM}}$ filter (see Figure 8) (NO fluxes: 0.2 vs. $0.01 \times 10^{-10} \mathrm{~mol} \cdot \mathrm{cm}^{-2} \cdot \mathrm{min}^{-1}$ ). Moreover, in combining the most efficient candidate PEI$\mathrm{PRO} / \mathrm{NO}$ with this dialysis set-up, even higher NO fluxes can be obtained (up to $0.5 \times 10^{-10}$ $\left.\mathrm{mol} \cdot \mathrm{cm}^{-2} \cdot \mathrm{min}^{-1}\right)$, within the range of the physiological NO flux level $\left(0.5-4 \times 10^{-10} \mathrm{~mol}\right.$. $\left.\mathrm{cm}^{-2} \cdot \mathrm{min}^{-1}\right)^{7}$ from endothelial cells. The interfacial NO release levels as well as the NO release efficiency can be enhanced even further through optimization of the dialysis set-up/ experiment conditions (i.e., fine-tune dialysate solution $\mathrm{pH}$, increase length and temperature of the mixing loop and etc.). Indeed, this latter combination was chosen as the primary proofof-concept candidate for the ongoing in vivo animal studies of the NO-release dialysis experiments at the University of Michigan Medical School.

It should be noted that the basic concept of releasing NO through the walls of the dialysis fibers used in hemodialyzers would not pose a risk of systematically decreasing the blood pressure of individuals who would potentially undergo dialysis using such an approach. Indeed, the low flux of NO that comes through the fibers from the dialysate solution (ideally equal to the normal fluxes that come from the endothelial cells that line the walls of all blood vessels) would immediately react with the far excess of hemoglobin in the blood. Hence, no free NO would exist to exert vasodilation effects downstream in the patient's body after the blood passes through the dialysis unit.

\section{Leaching Studies}

In addition to the desired $\mathrm{N}$-diazeniumdiolate moieties, a given amount of nitrite species also form within the NO adduct structures during synthesis and was found to be released into the surrounding bathing solution, ${ }^{15}$ and further diffuse through the membranous fibers to the blood side of the dialyzer. The initial nitrite (a minor side-product during NO addition and following workup ${ }^{15}$ ) released with time from three NO donors $(\mathbf{5}, \mathbf{8}$ and $\mathbf{1 1})$ was measured using the Griess assay 30 (see Figure $5 \mathrm{~s}$ in the Supporting Information). Such nitrite measurements were conducted in basic and oxygen-free conditions where no (or minimal) NO release and subsequent oxidation can occur, as NO could be oxidized to nitrite, yielding false values for the inherent nitrite levels in the polymeric NO donor preparations. It was found that the three polymeric compounds have total nitrite release potentials of (5) $1.00 \pm 0.02$, (8) $0.67 \pm 0.02$ and (11) $0.58 \pm 0.03 \mu \mathrm{mol} / \mathrm{mg}$, respectively. These values are very small compared to the total NO release values of the polymers (see Table 1 ). At the 4 -h point, each milligram of the compound can release an accumulated amount of nitrite of $0.77 \pm 0.02,0.21 \pm 0.01$ and 0.11 $\pm 0.01 \mu \mathrm{mol}$, respectively. In a 4-h dialysis leaching test experiment using (5), approx. $120 \mathrm{mg}$ of NO donor was initially used with $1.32 \mathrm{~L}$ of dialysate solution, which should make the final nitrite concentration in the dialysate solution to be $70 \mu \mathrm{M}(0.77 \mu \mathrm{mol} / \mathrm{mg} \times 120 \mathrm{mg} / 1.32 \mathrm{~L})$ at the end of the dialysis. In fact, on the blood side, the actual nitrite concentration in $150 \mathrm{~mL}$ of "blood" (deoxygenated PBS solution) at the end of the 4-h dialysis was found to be ca. 10 $\mu \mathrm{M}$, only $14 \%$ of the theoretical/possible leachable value. In the real NO-release hemodialysis experiment using the same set-up, the nitrite concentration may be higher due to the oxidation reaction of the released $\mathrm{NO}$ with the oxygen in the blood. Actually, nitrite ion is NO's primary oxidation product at physiological $\mathrm{pH}$ and a normal constituent present in abundance in human physiological fluids (between 0.5 and $21 \mu \mathrm{M}$ in the plasma of healthy human individuals 40 ,

41 ). Indeed, recently, a growing body of evidence suggests that the nitrite anion may represent the largest intravascular and tissue storage form of NO. ${ }^{42}$

The potential leaching of the polyamines, hydrolytic products of the water-soluble polymeric NO donors through the dialysis fiber into the blood side, was also examined. It should be noted that in vitro testing conducted by the dialyzer manufacturer has already proved that macromolecules with small sieving coefficients (i.e., 0.030 for albumin, $\mathrm{Mw}=65,000$ ) have much less chance of leaching than small molecules (i.e., 0.99 for urea, $\mathrm{Mw}=60$ ). In a dialysis 
experiment using $\mathrm{HMwPEI} / \mathrm{NO}(\mathbf{5})$ as the dialysate additive, the presence of polyamine leachables on the blood-side (10 mM PBS buffer, $\mathrm{pH}$ 7.4) was measured at intervals of $60 \mathrm{~min}$ for $4 \mathrm{~h}$ (targeted dialysis time). After treatments with FQCA, the fluorescence intensities of the PBS buffer at the selected intervals were found to be nearly the same as the control (blank PBS), indicating no evidence of detectable polymer leaching through the dialysis fiber walls.

\section{Conclusions}

Three different water-soluble poly(ethylenimine)-based NO releasing agents were designed, synthesized and characterized for potential use as NO release agents in hemodialysis systems. It has been shown that water-soluble polymers with up to $4.15 \mu \mathrm{mol} / \mathrm{mg}$ of total NO release potential can be prepared and the rates of NO release can be modulated by the specific structure of the polymer, as well as experimental factors such as $\mathrm{pH}$, temperature and use of exogenous additives (e.g., the sodium salt of poly(acrylic acid)). When used as NO generating reagents in the dialysate fluid of commercial hemodialysis units, the new diazeniumdiolated polymers were found to provide a steady and controllable NO interfacial fluxes through the fibers of such devices. Use of the most efficient NO donor candidate, PEI-PRO/NO, provides physiological levels of NO flux $\left(0.5 \times 10^{-10} \mathrm{~mol} \cdot \mathrm{cm}^{-2} \cdot \mathrm{min}^{-1}\right)$ at the membranous fiber/blood interface within the dialyzer. Thus, improved blood compatibility of dialysis fibers in the absence of other anticoagulants (i.e., heparin or citrate) during the dialysis treatment may be possible without concern of either clotting or excess bleeding. Although no significant evidence was found that the new PEI-based polymers crossed the dialysis fiber walls to the blood side, increasing the molecular weight of the NO donors would further ensure safe dialysis with the proposed method. At the same time, additional research is required to develop water-soluble polymeric NO donors with even faster release kinetics. Indeed, at present, given the short residence time of the water-soluble polymeric NO donors in the dialysis unit (minutes), a substantial fraction of the loaded NO is never used to potentially reduce thrombosis. Hence, creating macromolecular NO donors with $t_{1 / 2}$ values on the order of 2-5 minutes would provide the ideal polymers for the dialysis application. Nevertheless, until such new polymers can be prepared, the water-soluble polymeric NO donors described here are being examined in animal experiments to further assess this NO-release dialysis concept in terms of blood compatibility of dialysis fibers and any toxicity issues associated with the use of such polymeric NO donors in dialysis therapies.

\section{Supplementary Material}

Refer to Web version on PubMed Central for supplementary material.

\section{Acknowledgements}

We gratefully acknowledge the NIH (EB-000783 and HD-015434) and Michigan Critical Care Consultants, Inc., for supporting this work.

\section{References}

1. Salzman, EW.; Merrill, EW. Hemostasis and Thrombosis. Colman, RW.; Hirsh, J.; Marder, VS.; Salzman, EW., editors. JB Lippincott; Philadelphia: 1987. p. 1335-1347.

2. Kim YG. Nephrology 2003;8:S23-S27. [PubMed: 15012687]

3. Janssen M, vanderMeulen J. Neth J Med 1996;48:198-207. [PubMed: 8710039]

4. Lohr JW, Schwab SJ. J Am Soc Nephrol 1991;2:961-975. [PubMed: 1760540]

5. Pinnick RV, Wiegmann TB, Diederich DA. N Engl J Med 1983;308:258-261. [PubMed: 6848936]

6. Faber LM, Devries P, Oe PL, Vandermeulen J, Donker AJM. Neth J Med 1990;37:219-224. [PubMed: 2074914] 
7. Radomski MW, Palmer RMJ, Moncada S. Biochem Biophys Res Commun 1987;148:1482-1489. [PubMed: 2825688]

8. Radomski MW, Palmer RMJ, Moncada S. Br J Pharmacol 1987;92:639-646. [PubMed: 3322462]

9. Siney L, Lewis MJ. Eur J Pharmacol 1992;229:223-226. [PubMed: 1283374]

10. Sneddon JM, Vane JR. Proc Natl Acad Sci U S A 1988;85:2800-2804. [PubMed: 3258664]

11. Annich GM, Meinhardt JP, Mowery KA, Ashton BA, Merz SI, Hirschl RB, Meyerhoff ME, Bartlett RH. Crit Care Med 2000;28:915-920. [PubMed: 10809259]

12. Batchelor MM, Reoma SL, Fleser PS, Nuthakki VK, Callahan RE, Shanley CJ, Politis JK, Elmore J, Merz SI, Meyerhoff ME. J Med Chem 2003;46:5153-5161. [PubMed: 14613318]

13. Fleser PS, Nuthakki VK, Malinzak LE, Callahan RE, Seymour ML, Reynolds MM, Merz SI, Meyerhoff ME, Bendick PJ, Zelenock GB, Shanley CJ. J Vasc Surg 2004;40:803-811. [PubMed: 15472611]

14. Zhang HP, Annich GM, Miskulin J, Osterholzer K, Merz SI, Bartlett RH, Meyerhoff ME. Biomaterials 2002;23:1485-1494. [PubMed: 11829445]

15. Zhang HP, Annich GM, Miskulin J, Stankiewicz K, Osterholzer K, Merz SI, Bartlett RH, Meyerhoff ME. J Am Chem Soc 2003;125:5015-5024. [PubMed: 12708851]

16. Frost MC, Rudich SM, Zhang HP, Maraschio MA, Meyerhoff ME. Anal Chem 2003;75:1037-1037.

17. Frost MC, Reynolds MM, Meyerhoff ME. Biomaterials 2005;26:1685-1693. [PubMed: 15576142]

18. Reynolds MM, Frost MC, Meyerhoff ME. Free Radic Biol Med 2004;37:926-936. [PubMed: 15336308]

19. Davies KM, Wink DA, Saavedra JE, Keefer LK. J Am Chem Soc 2001;123:5473-5481. [PubMed: 11389629]

20. Saavedra JE, Southan GJ, Davies KM, Lundell A, Markou C, Hanson SR, Adrie C, Hurford WE, Zapol WM, Keefer LK. J Med Chem 1996;39:4361-4365. [PubMed: 8893830]

21. Waterhouse DJ, Saavedra JE, Davies KM, Citro ML, Xu X, Powell DA, Grimes GJ, Potti GK, Keefer LK. J Pharm Sci 2006;95:108-115. [PubMed: 16315224]

22. Smith DJ, Chakravarthy D, Pulfer S, Simmons ML, Hrabie JA, Citro ML, Saavedra JE, Davies KM, Hutsell TC, Mooradian DL, Hanson SR, Keefer LK. J Med Chem 1996;39:1148-1156. [PubMed: 8676352]

23. Mowery KA, Schoenfisch MH, Saavedra JE, Keefer LK, Meyerhoff ME. Biomaterials 2000;21:921. [PubMed: 10619674]

24. Zhou ZR, Meyerhoff ME. Biomaterials 2005;26:6506-6517. [PubMed: 15941584]

25. Nablo BJ, Prichard HL, Butler RD, Klitzman B, Schoenfisch MH. Biomaterials 2005;26:6984-6990. [PubMed: 15978663]

26. Nablo BJ, Rothrock AR, Schoenfisch MH. Biomaterials 2005;26:917-924. [PubMed: 15353203]

27. Marxer SM, Rothrock AR, Nablo BJ, Robbins ME, Schoenfisch MH. Chem Mater 2003;15:41934199.

28. Frost MC, Meyerhoff ME. Journal of Biomedical Materials Research Part A 2005;72A:409-419. [PubMed: 15682428]

29. Pulfer SK, Ott D, Smith DJ. J Biomed Mater Res 1997;37:182-189. [PubMed: 9358310]

30. Schmidt, HHHW.; Kelm, M. Methods in Nitric Oxide Research. Feelisch, M.; Stamler, JS., editors. John Wiley \& Sons; West Sussex: 1996. p. 491-497.

31. Drago RS, Karstett Br. J Am Chem Soc 1961;83:1819-1822.

32. Zhou ZR, Meyerhoff ME. Biomacromolecules 2005;6:780-789. [PubMed: 15762642]

33. Kostyukovskii YL, Melamed DB. Usp Khim 1988;57:625-655.

34. Keefer LK, Flippen-Anderson JL, George C, Shanklin AP, Dunams TA, Christodoulou D, Saavedra JE, Sagan ES, Bohle DS. Nitric Oxide: Biol Chem 2001;5:377-394.

35. Monien BH, Cheang KI, Desai UR. J Med Chem 2005;48:5360-5368. [PubMed: 16078853]

36. Monien BH, Desai UR. J Med Chem 2005;48:1269-1273. [PubMed: 15715496]

37. Miranda KM, Katori T, de Holding CLT, Thomas L, Ridnour LA, MeLendon WJ, Cologna SM, Dutton AS, Champion HC, Mancardi D, Tocchetti CG, Saavedra JE, Keefer LK, Houk KN, Fukuto JM, Kass DA, Paolocci N, Wink DA. J Med Chem 2005;48:8220-8228. [PubMed: 16366603] 
38. Nakatsubo N, Kojima H, Kikuchi K, Nagoshi H, Hirata Y, Maeda D, Imai Y, Irimura T, Nagano T. FEBS Lett 1998;427:263-266. [PubMed: 9607324]

39. Espey MG, Miranda KM, Thomas DD, Wink DA. Free Radic Biol Med 2002;33:827-834. [PubMed: 12208370]

40. Leone AM, Francis PL, Rhodes P, Moncada S. Biochem Biophys Res Commun 1994;200:951-957. [PubMed: 8179632]

41. Ueda T, Maekawa T, Sadamitsu D, Oshita S, Ogino K, Nakamura K. Electrophoresis 1995;16:10021004. [PubMed: 7498119]

42. Gladwin MT, Schechter AN, Kim-Shapiro DB, Patel RP, Hogg N, Shiva S, Cannon RO, Kelm M, Wink DA, Espey MG, Oldfield EH, Pluta RM, Freeman BA, Lancaster JR, Feelisch M, Lundberg JO. Nature Chemical Biology 2005;1:308-314. 


\section{Dialysate with}

water-soluble

$\mathrm{NO}$ releasing polymer

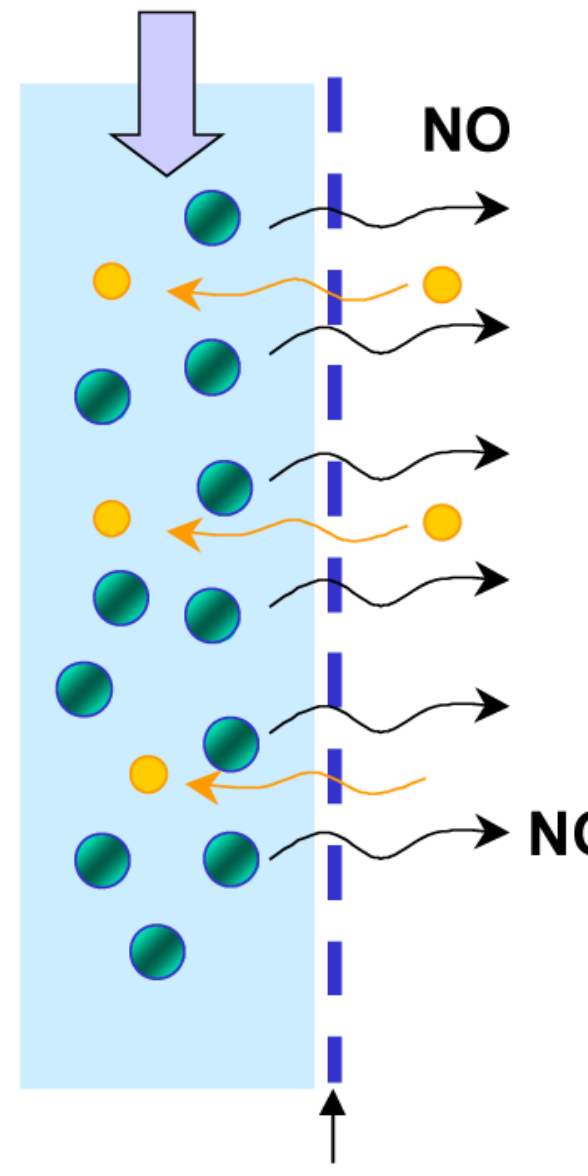

\section{Dialysis fiber wall}

\section{Red Blood Cell}

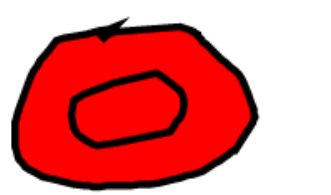

\section{Toxic species}

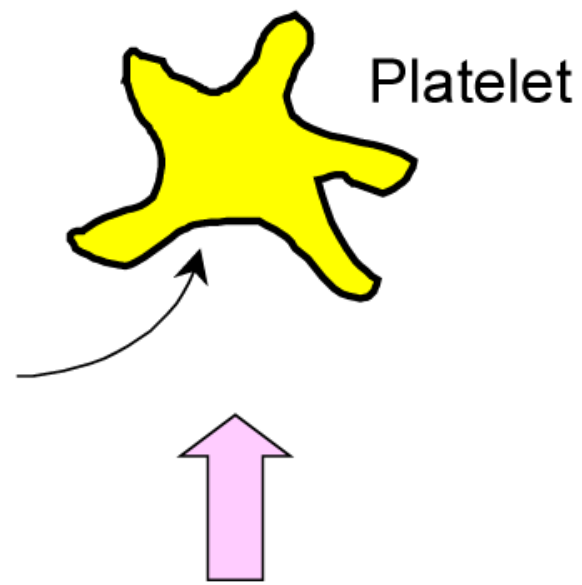

Blood flow

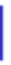

I

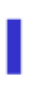

Figure 1.

A schematic diagram illustrating the concept of improving the blood compatibility of hemodialyzer fibers via NO-release from a polymeric NO releasing agent added to the flowing dialysate solution. 


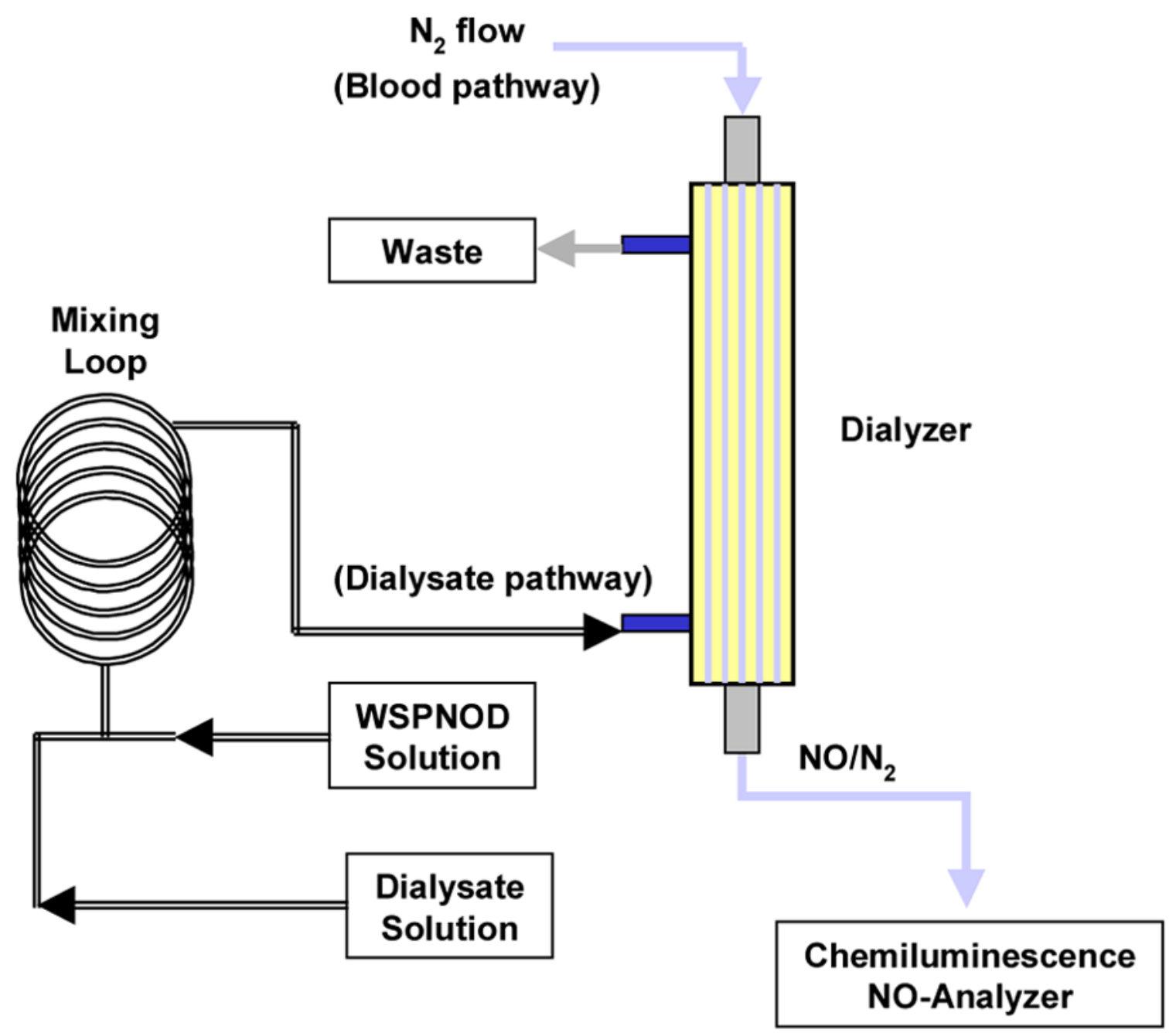

Figure 2.

A schematic diagram of the NO-release dialysis set-up (WSPNOD: water-soluble polymeric NO donor). 

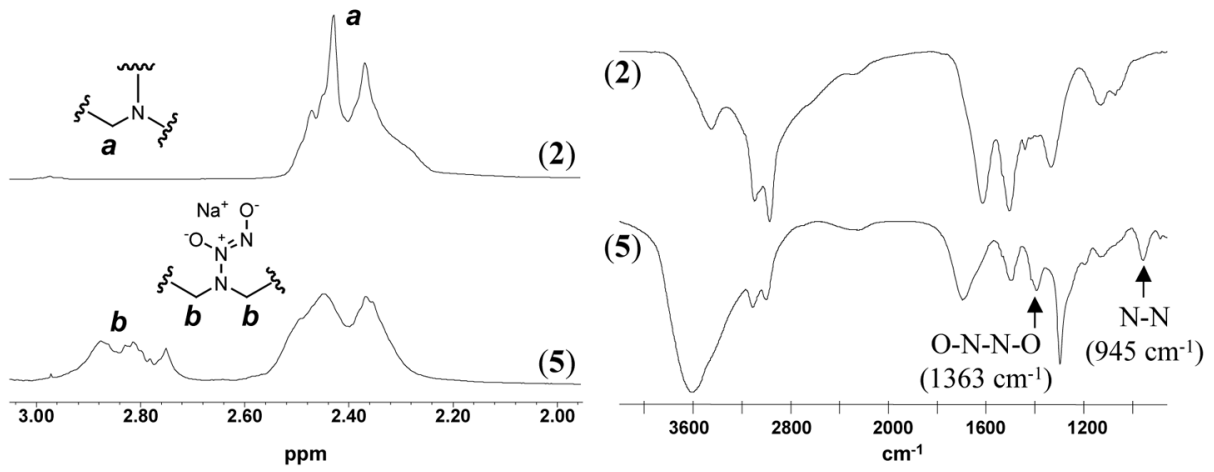

Figure 3.

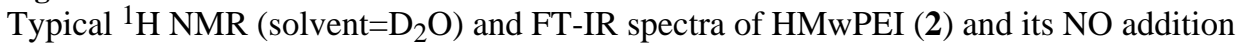
product HMwPEI/NO (5). 


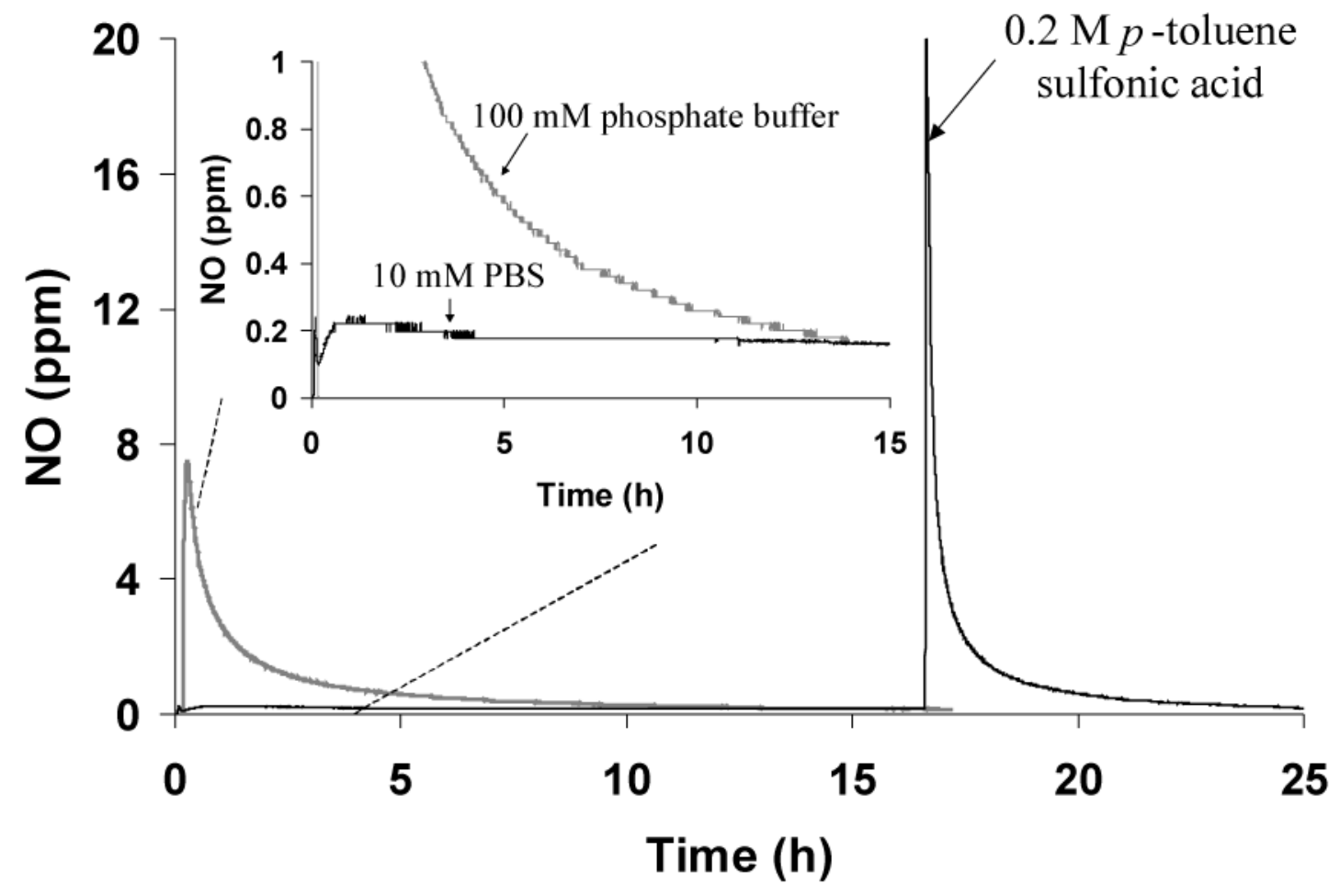

Figure 4.

NO release from HMwPEI/NO (5) in phosphate buffers with various buffer capacities. The NO levels detected were normalized as a value per $1 \mathrm{mg}$ of HMwPEI/NO. The measurements were performed in deoxygenated buffers at $37^{\circ} \mathrm{C}$ via the CL NOA. 


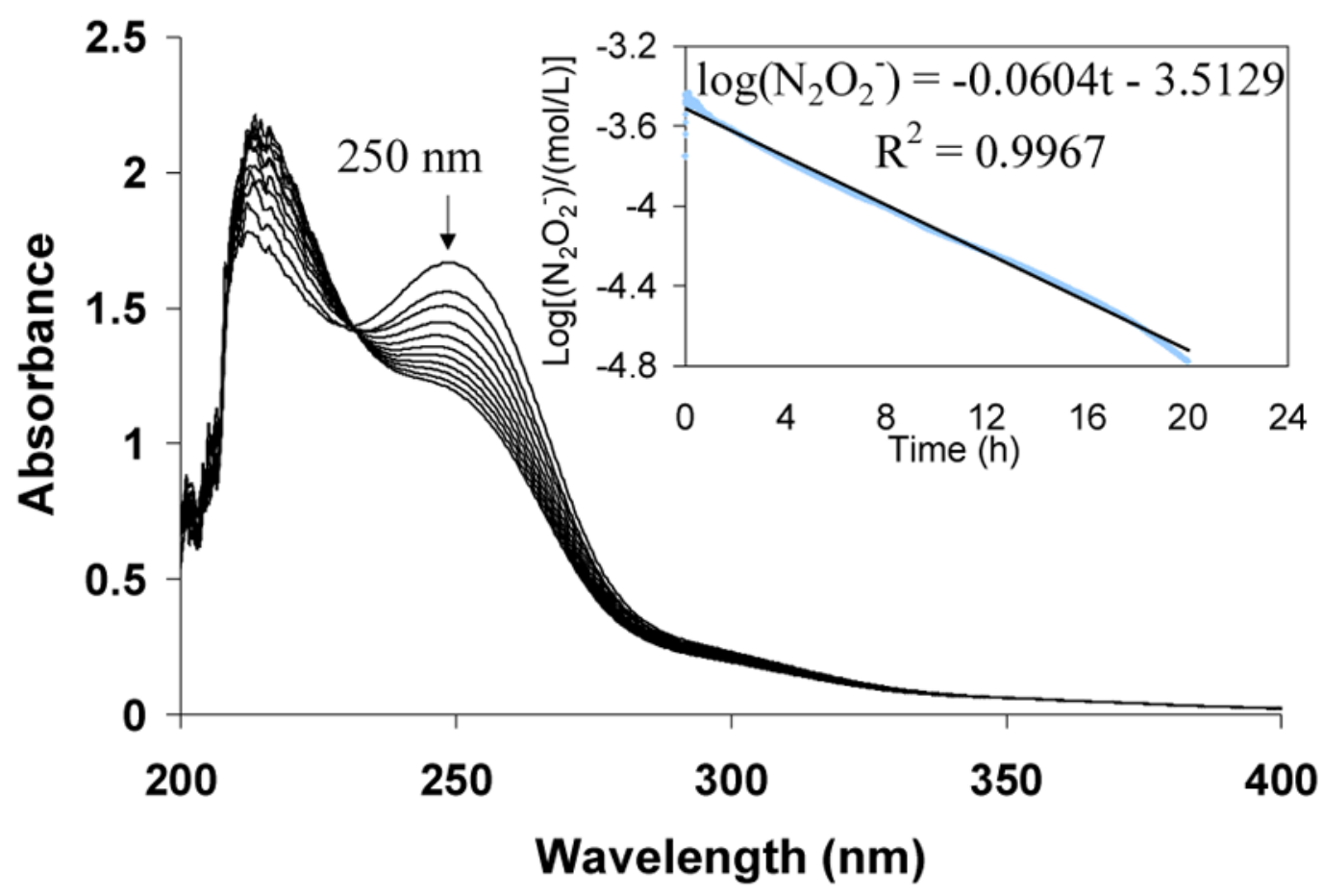

Figure 5.

Decomposition kinetic study of diazeniumdiolates within polymer HMwPEI/NO (5) as measured via UV in $100 \mathrm{mM}$ deoxygenated phosphate buffer $(0.1 \mathrm{mg} / \mathrm{mL}, \mathrm{pH} 7.4)$ at $26{ }^{\circ} \mathrm{C}$; each spectrum was collected at a 10 min interval. Inset: Plot used to determine a near-firstorder rate constant of $\mathrm{k}_{\mathrm{D}}=3.9 \times 10^{-5} \mathrm{~s}^{-1}$ (each absorbance data was collect at $\lambda=250 \mathrm{~nm}$ with an interval of $15 \mathrm{~s}$ ). 


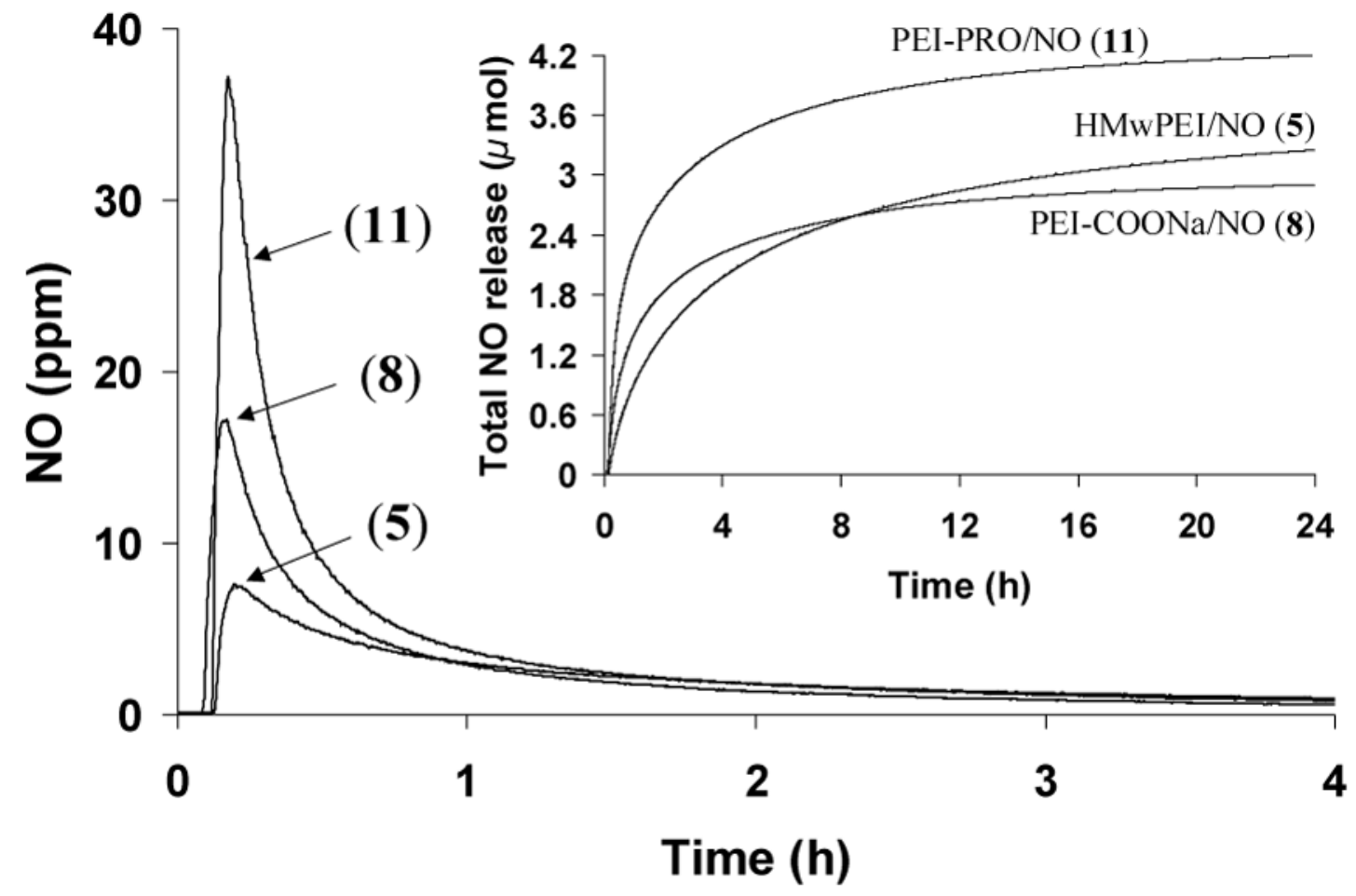

Figure 6.

NO release from $\mathrm{HMwPEI} / \mathrm{NO}(\mathbf{5}), \mathrm{PEI}-\mathrm{COONa} / \mathrm{NO}(\mathbf{8})$ and PEI-PRO/NO (11) as measured in deoxygenated phosphate buffer $(\mathrm{pH} 7.4,100 \mathrm{mM})$ at $37^{\circ} \mathrm{C}$ via the CL NOA; Inset: Total NO release of the three compounds. All the NO amounts detected were normalized as a value per $1 \mathrm{mg}$ of donor. 

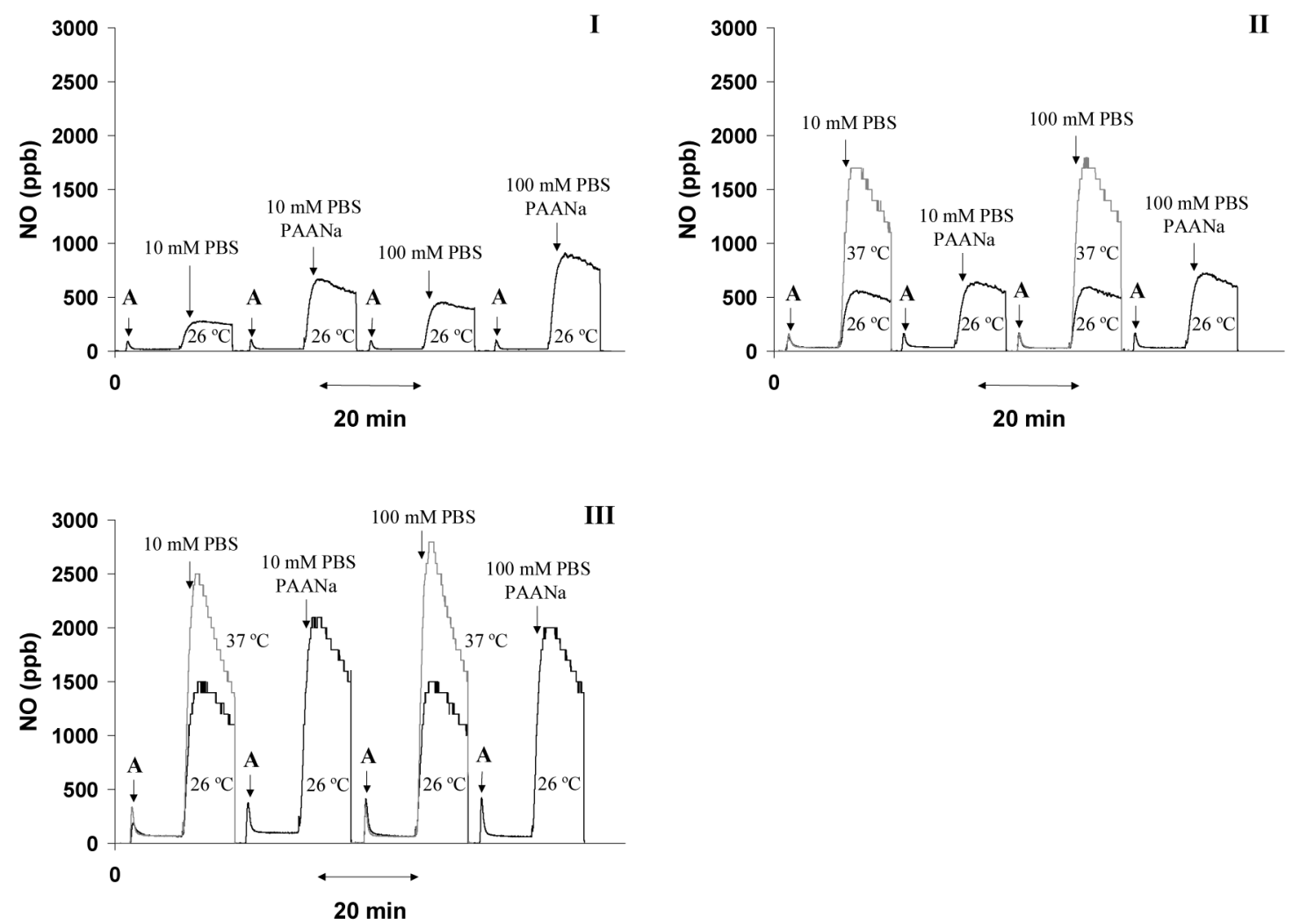

Figure 7.

Proton-stimulated spontaneous NO releases as measured at 26 and $37^{\circ} \mathrm{C}$ via the CL NOA by mixing a $100 \mu \mathrm{L}$ solution of PEI/NO (I), PEI-COONa/NO (II) or PEIPRO/NO (III)

( $\mathbf{A}=$ addition of an NO donor solution: $1 \mathrm{mg} / \mathrm{mL}$ in phosphate buffer, $\mathrm{pH} 8.0$ ) with a $3300 \mu \mathrm{L}$ of $10 \mathrm{mM}$ PBS or $100 \mathrm{mM}$ phosphate buffer $(\mathrm{pH} 7.4)$ in the presence and absence of PAANa additive $(30 \mu \mathrm{g} / \mathrm{mL})$. 

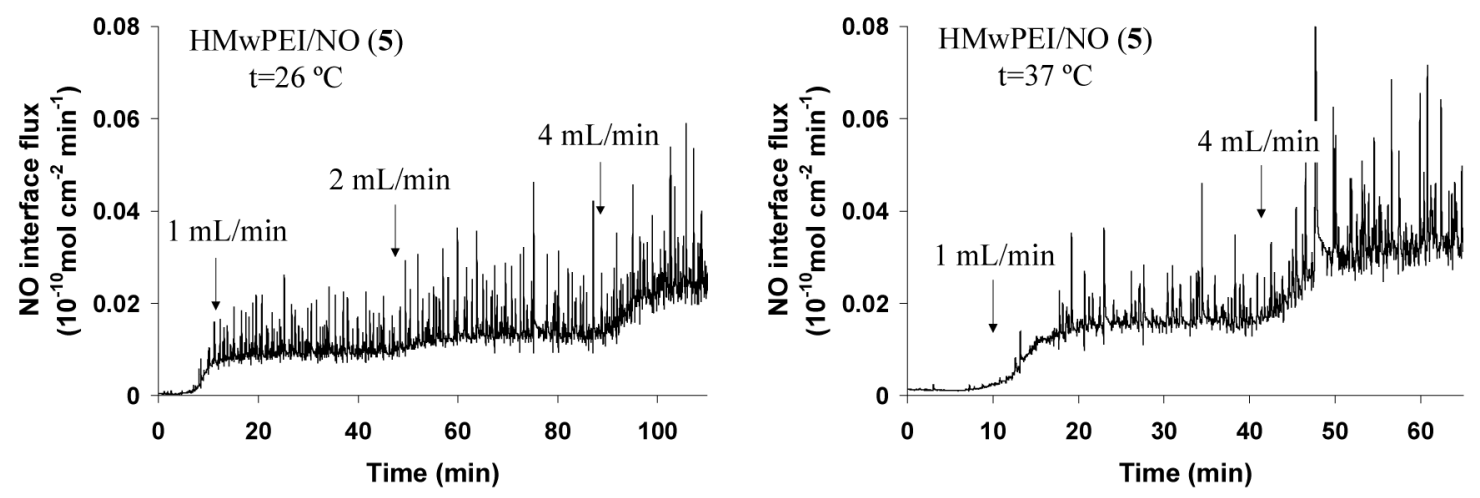

Figure 8.

Interfacial NO fluxes generated across the dialysis membranous fibers within a Baxter ${ }^{\mathrm{TM}}$ dialyzer at room/physiological pre-heating temperature as measure via the CL NOA. HMwPEI/ NO (5): $1 \mathrm{mg} / \mathrm{mL}$ in phosphate buffer $(\mathrm{pH} 8)$ at a rate of $1-4 \mathrm{~mL} / \mathrm{min}$; dialysate solution: PBS buffer (pH 7.4) at a controlled rate of $33 \mathrm{~mL} / \mathrm{min}$. 

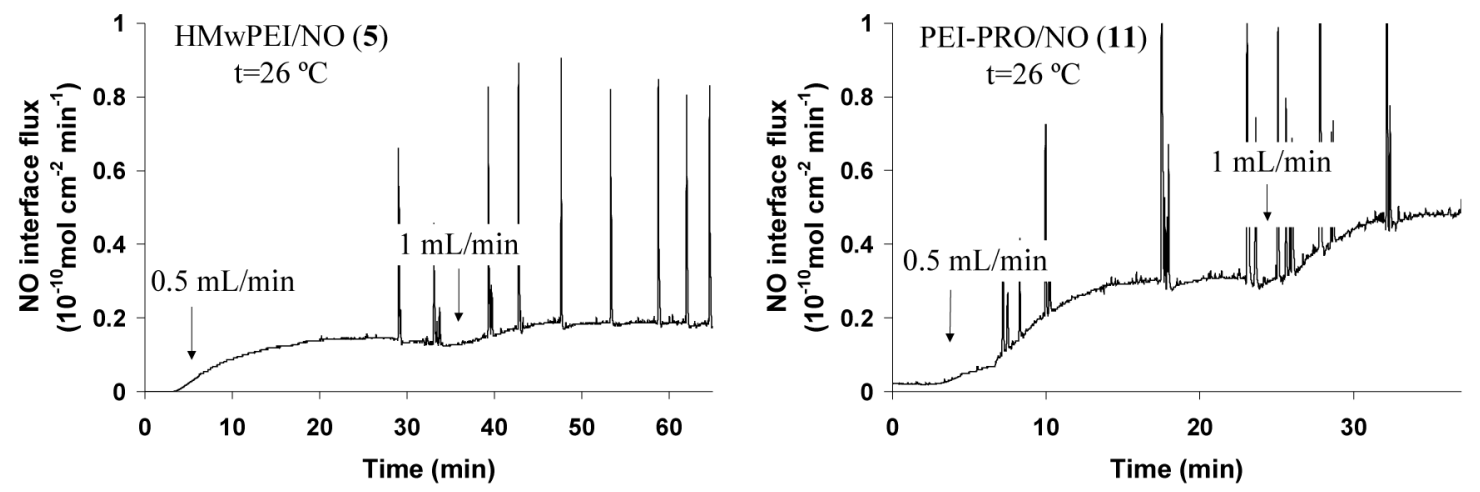

Figure 9.

Interfacial NO fluxes generated across the dialysis membranous fibers within a Minntech ${ }^{\mathrm{TM}}$ mini-filter at room temperature as measured via the CL NOA. HMwPEI/NO (5) and PEI-PRO/ NO (11): $1 \mathrm{mg} / \mathrm{mL}$ in phosphate buffer $(\mathrm{pH} 8)$ at a rate of $0.5-1 \mathrm{~mL} / \mathrm{min}$; dialysate solution: PBS buffer ( $\mathrm{pH} \mathrm{7.4)}$ at a controlled rate of $15 \mathrm{~mL} / \mathrm{min}$. 


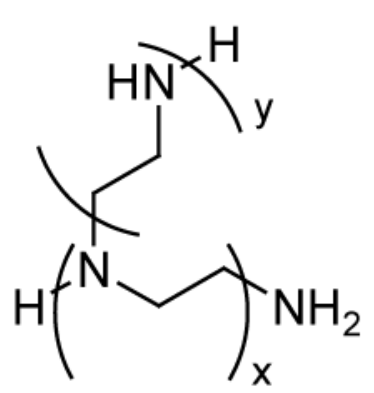

\section{LMwPEI HMwPEI}

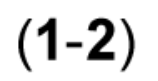

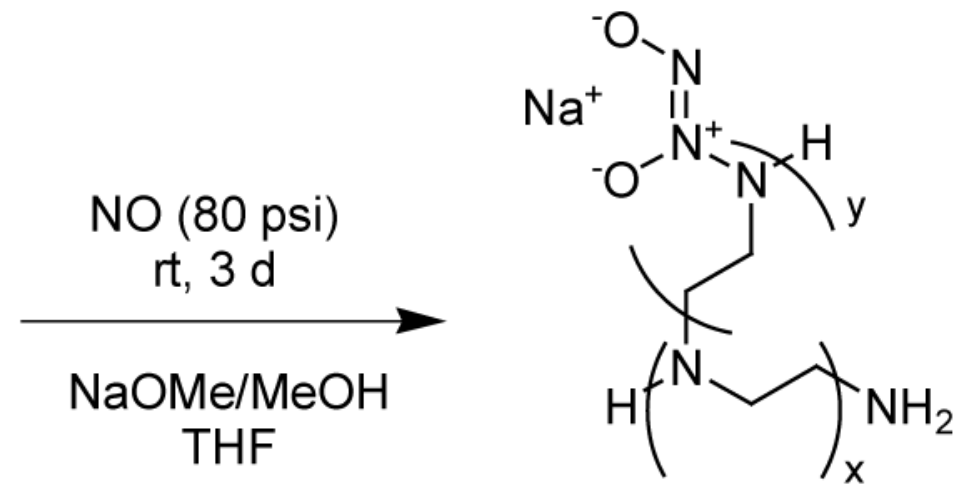

PEI/NO

(3-6)

Scheme 1.

Synthesis of diazeniumdiolated branched PEIs. 


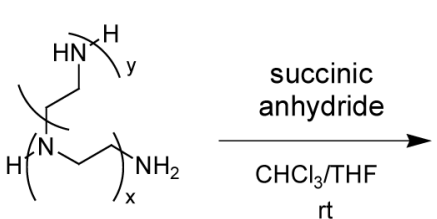

HMwPEI

(2)

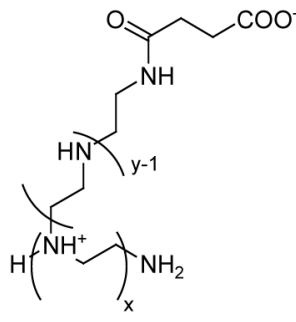

PEI-COOH

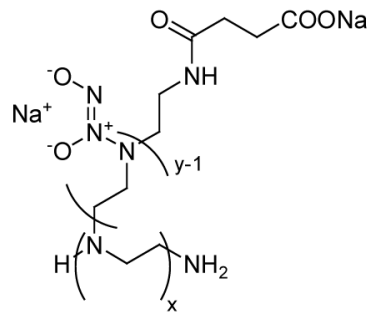

PEI-COONa/NO

Scheme 2.

Synthesis of diazeniumdiolated carboxylated-PEI. 
<smiles>[X]C(N)CNC(C)CNCC</smiles>

HMwPEI

(2)

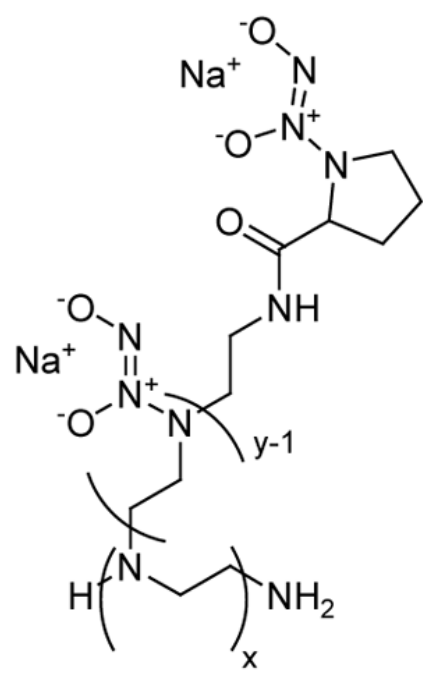

PEI-PRO/NO

(11)

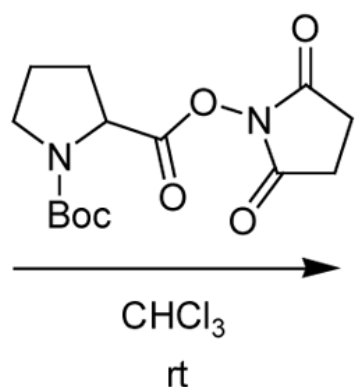

PEI-PRO-BOC

(9)

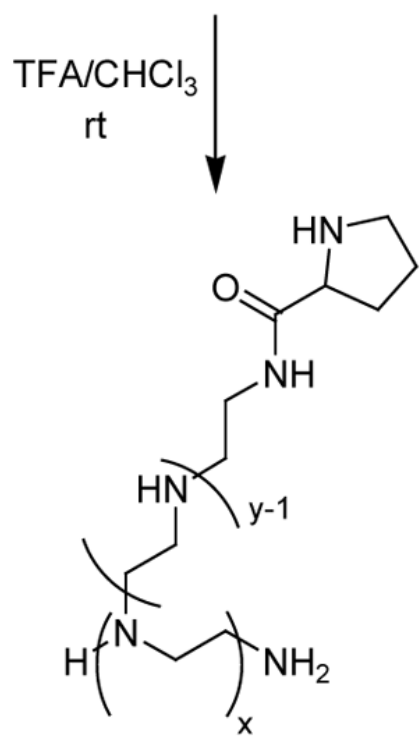

PEI-PRO
$\mathrm{NO}(80 \mathrm{psi})$

rt, $3 \mathrm{~d}$

$\mathrm{NaOMe} / \mathrm{MeOH}$

THF

Scheme 3.

Synthesis of diazeniumdiolated L-proline-incorporated PEI. 


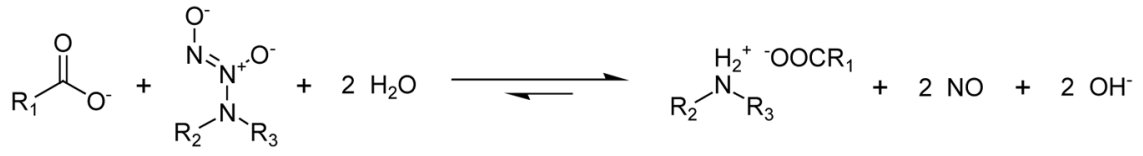

Scheme 4.

Proposed mechanism by which use of carboxylate site speeds NO release. 
Table 1

Yields and chemiluminescence (CL) characterization of the NO addition products of PEIs and their derivatives.

\begin{tabular}{lcrr}
\hline Compound & NaOMe & Yield (\%) & Total NO release $\boldsymbol{b}_{(\boldsymbol{\mu m o l} / \mathbf{m g})} \boldsymbol{c}_{(\mathbf{D} \%)}^{\boldsymbol{d}}$ \\
\hline LMwPEI/NO (3) & $0.2 \mathrm{eq}$ & 49.2 & $2.71 \pm 0.28(18.8 \%)$ \\
LMwPEI/NO (4) & $1.0 \mathrm{eq}$ & 74.8 & $2.76 \pm 0.06(19.2 \%)$ \\
HMwPEI/NO (5) & $0.2 \mathrm{eq}$ & $5.74 \pm 0.41(24.9 \%)$ & $3.84 \pm 0.20(26.8 \%)$ \\
HMwPEI/NO (6) & $1.0 \mathrm{eq}$ & $2.92 \pm 0.05(24.5 \%)$ \\
PEI-COONa/NO (8) & $1.3 \mathrm{eq}$ & 68.0 & $4.15 \pm 0.16(32.2 \%)$ \\
PEI-PRO/NO (11) & $1.3 \mathrm{eq}$ & 69.7 & 61.2 \\
\hline
\end{tabular}

\footnotetext{
${ }^{a}$ Sodium methoxide used for NO addition with respect with total amine/carboxylate sites;

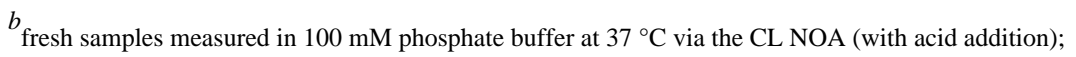

$c_{\text {Mean }} \pm \mathrm{SD}(\mathrm{n} \geq 3)$

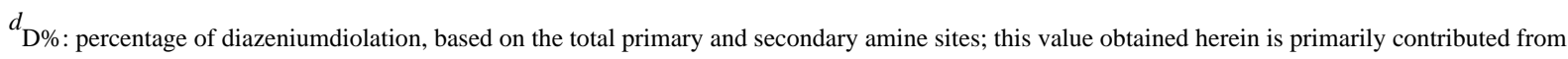
the stable secondary amine diazeniumdiolates, given primary amine diazeniumdiolates are very unstable and may have undergone decomposition before NOA measurements. 31
} 
Table 2

Decomposition parameters of the water-soluble diazeniumdiolated polymers.

\begin{tabular}{lllc}
\hline Compound & aqueous media & $\boldsymbol{k}_{\mathbf{D}}\left(\times \mathbf{1 0}^{-\mathbf{5}} \mathbf{s}^{-\mathbf{1}}\right)$ & $\boldsymbol{t}_{\mathbf{1 / 2}}^{\boldsymbol{a}, \boldsymbol{c}}(\mathbf{m i n})$ \\
\hline HMwPEI/NO (5) & $100 \mathrm{mM}$ phosphate buffer $b .0$ & $192.0 \pm 1.7$ \\
HMwPEI/NO (5) & PAANa solution & 16.1 & $72.0 \pm 3.0$ \\
PEI-COONa/NO (8) & 100 mM phosphate buffer & 19.4 & $59.4 \pm 0.8$ \\
PEI-PRO/NO (11) & 100 mM phosphate buffer & 24.1 & $48.0 \pm 2.5$ \\
& & & \\
\hline
\end{tabular}

${ }^{a}$ measured at $37^{\circ} \mathrm{C}$ via the CL NOA;

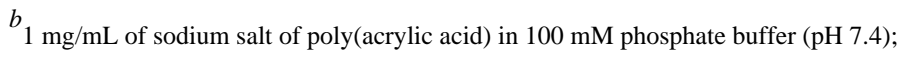

$c_{\text {Mean }} \pm \mathrm{SD}(\mathrm{n} \geq 3)$. 